\title{
New reactor cavity cooling system having passive safety features using novel shape for HTGRs and VHTRs
}

\author{
Kuniyoshi Takamatsu \\ Japan Atomic Energy Agency \\ 4002 Narita-cho, \\ Oarai-machi, Higashiibaraki-gun, \\ Ibaraki-ken, 311-1393, JAPAN \\ takamatsu.kuniyoshi@jaea.go.jp \\ +81-29-266-7718 \\ Rui Hu \\ Argonne National Laboratory \\ 9700 South Cass Avenue \\ Argonne, IL 60439 \\ rhu@anl.gov \\ $+1-630-252-1461$
}

\begin{abstract}
A new, highly efficient reactor cavity cooling system (RCCS) with passive safety features without a requirement for electricity and mechanical drive is proposed for high temperature gas cooled reactors (HTGRs) and very high temperature reactors (VHTRs). The RCCS design consists of continuous closed regions; one is an ex-reactor pressure vessel (RPV) region and another is a cooling region having heat transfer area to ambient air assumed at $40\left({ }^{\circ} \mathrm{C}\right)$. The RCCS uses a novel shape to efficiently remove the heat released from the RPV with radiation and natural convection. Employing the air as the working fluid and the ambient air as the ultimate heat sink, the new RCCS design strongly reduces the possibility of losing the heat sink for decay heat removal. Therefore, HTGRs and VHTRs adopting the new RCCS design can avoid core melting due to overheating the fuels. The simulation results from a commercial CFD code, STAR-CCM+, show that the temperature distribution of the RCCS is within the temperature limits of the structures, such as the maximum operating temperature of the RPV, $713.15(\mathrm{~K})=440\left({ }^{\circ} \mathrm{C}\right)$, and the heat released from the RPV could be removed safely, even during a loss of coolant accident (LOCA). When the RCCS can remove $600(\mathrm{~kW})$ of the rated nominal state even during LOCA, the safety review for building the HTTR could confirm that the temperature distribution of the HTTR is within the temperature limits of the structures to secure structures and fuels after the shutdown because the large heat capacity of the graphite core can absorb heat from the fuel in a short period. Therefore, the capacity of the new RCCS design would be sufficient for decay heat removal.
\end{abstract}

\section{KEYWORDS}

Thermal-hydraulics, RCCS, Passive safety, HTGR, VHTR, RPV, Core meltdown, LOCA, Depressurization accident 


\section{INTRODUCTION}

\subsection{Fukushima Daiichi nuclear disaster}

The Tōhoku earthquake occurred at 14:46 on Friday, 11 March 2011. The earthquake triggered a 13 to $15(\mathrm{~m})$ maximum height tsunami that arrived approximately 50 minutes later. The waves overtopped the Fukushima Daiichi Nuclear Power Plant's seawall of 10 (m), flooding the basements of the turbine buildings and disabling the emergency diesel generators.

The heat released from the core or the RPV could not be actively removed. The RPV had been damaged during the disaster, and "significant amounts" of molten fuel had fallen into the bottom of the Primary Containment Vessel (PCV) - the molten fuel after the core meltdown had eroded the concrete of the PCV.

Therefore, a passive decay heat removal system is essential to avoid the loss of a heat sink and a core meltdown. A new RCCS using novel shape is proposed for this purpose because it can always be reliable, even during a loss of power. The RCCS can stably and passively remove a part of the heat released from the RPV at the rated operation and the decay heat after reactor shutdown. Specifically, emergency power generators are not required and the decay heat can be removed passively for a long time, even forever, when the decay heat quickly decreases below the heat removal rate of the RCCS.

\subsection{HTGRs and VHTRs}

The Next Generation Nuclear Plant (NGNP) project was formally established on the basis of developing 4th generation nuclear reactors that are greener and safer. In the NGNP project, the conceptual design is a helium-cooled, graphite moderated reactor with a ceramic core. The design is similar to HTGRs but the goal is to extend to outlet coolant temperatures up to 1000 $\left({ }^{\circ} \mathrm{C}\right)$, above an outlet coolant temperature for the HTGR. A VHTR is loosely defined as any reactor with the outlet coolant temperature of $1000\left({ }^{\circ} \mathrm{C}\right)$ or above. The increase in the outlet coolant temperature will increase electrical generation efficiency and better thermal conditions for process heat applications.

Conventional RCCSs for an HTGR or the HTTR have adopted forced convection or the circulation of water with electrical or mechanical pumps. However, when pipes of the RCCS are cracked during accident conditions, water leaks from the cracks, which decreases heat removal due to forced convection. Moreover, forced convection cannot remove heat during a loss of power.

Conversely, the new RCCS for a VHTR plans to adopt natural convection or the circulation of ambient air inhaled into ducts (Williams et al., 1994; Katanishi et al., 2004; Lomperski et al., 2011). The air absorbs heat released from the RPV and flows upward in the ducts due to the chimney effect and ultimately flows into the ambient air from the ducts.

The RCCS requires ducts longer than $60(\mathrm{~m})$ to enhance the chimney effect and increase the air velocity to promote natural convection or circulation until winds are strong; however, the maximum length of ducts is limited in the reactor building, and the air velocity has an upper limit due to the surface resistance of the ducts. Moreover, ambient air always flows into the ducts, and dust, including plants and insects, is accumulated in the ducts every day. The ducts 
soon rust and erode due to humidity and salty air; therefore, large amounts of capital need to be budgeted to maintain and replace the ducts.

Thus, this work proposes a new air-cooled RCCS design that does not use ducts. The design concept and initial analysis results are presented in the following sections.

\section{Concept design of RCCSs}

As an example, the RCCS concepts are examined with the targeted implementation in the JAEA's HTTR (Saito et al., 1994).

\subsection{Dimension of the HTTR}

The dimensions of the HTTR are shown as follows:

Table 1. Dimensions of the HTTR

\begin{tabular}{|l|l|}
\hline $\begin{array}{l}\text { The distance between the center of the core and the } \\
\text { surface on the RCCS, Radius }\end{array}$ & $3.86(\mathrm{~m})$ \\
\hline Diameter of the RCCS & $7.72(\mathrm{~m})$ \\
\hline Circumference of the RCCS Surface & $24.2531(\mathrm{~m})$ \\
\hline Height of the RCCS & $16.8574(\mathrm{~m})$ \\
\hline Heat transfer area of the RCCS & $408.84\left(\mathrm{~m}^{2}\right)$ \\
\hline Temperature on the RPV & $673.15(\mathrm{~K})=400\left({ }^{\circ} \mathrm{C}\right)$ \\
\hline Structure temperature of the RCCS & $\begin{array}{l}\text { Approximately } 373.15(\mathrm{~K})= \\
100\left({ }^{\circ} \mathrm{C}\right)\end{array}$ \\
\hline $\begin{array}{l}\text { The released heat from the RPV or the removed heat by } \\
\text { RCCS at the rated operation of 30 }(\mathbf{M W})\end{array}$ & $600-800(\mathrm{~kW})$ \\
\hline
\end{tabular}

The HTTR currently uses a forced convection water-cooled RCCS. The heat loss through the RPV at the rated operation is designed at $600(\mathrm{~kW})$ which is a required heat removal capability to secure structures and fuels after the shutdown.

However, we employ $800(\mathrm{~kW})$ including safety margin, $200(\mathrm{~kW})$.

The HTTR experiments showed that the temperature difference between the RPV $(673.15(\mathrm{~K})$ $=400\left({ }^{\circ} \mathrm{C}\right)$ ) and the structure of the RCCS (approximately $373.15(\mathrm{~K})=100\left({ }^{\circ} \mathrm{C}\right)$ ) is approximately $300(\mathrm{~K})$ for removing $800(\mathrm{~kW})$ by radiation and natural convection. Specifically, heat removal using only radiation relies entirely upon the above temperature difference of $300(\mathrm{~K})$.

In other words, when the temperature difference between the RPV and the structure of the RCCS is decreased, the amount of heat removed by radiation is decreased and $800(\mathrm{~kW})$ cannot be removed; therefore, the temperature of the structure of the RCCS needs to be 100 $\left({ }^{\circ} \mathrm{C}\right)$ for removing $800(\mathrm{~kW})$ by radiation.

\subsection{Depressurization accident as LOCA}

Moreover, when the RCCS can remove $600(\mathrm{~kW})$ of the rated nominal state even during LOCA, the safety review for building the HTTR could confirm that the temperature 
distribution of the HTTR is within the temperature limits of the structures to secure structures and fuels after the shutdown because the large heat capacity of the graphite core can absorb heat from the fuel in a short period.

The HTTR considered a depressurization accident as LOCA. A depressurization accident is initiated by the rupture of primary concentric hot gas duct at the RPV inlet nozzle. The reactor is scrammed immediately during this accident. In case of a depressurization accident, the primary coolant is released into the Containment Vessel (CV) through a break and forced cooling is lost after the reactor scram.

The forced circulation cooling system except for the RCCS will not be operated under this condition in order to prevent air from being sucked into the core due to forced convection. Therefore, the residual heat of the core is transferred to the RPV by natural convection, conduction and radiation. The transferred heat is removed from the surface of RPV to the RCCS mainly by radiation.

The corresponding temperature of the RPV increases more than $400\left({ }^{\circ} \mathrm{C}\right)$ for a short time during this accident and the corresponding temperature difference between the RPV and the RCCS structure also increases; therefore, the removal heat from the surface of RPV increases by radiation in proportion to the amount of $\left(T_{\mathrm{RPV}}^{4}-T_{\mathrm{RCCS}}^{4}\right)$ and then the temperature of the RPV decreases.

After the primary coolant pressure reaches the same value of helium/air mixture in the CV, the air in the $\mathrm{CV}$ enters the core due to natural convection and oxidizes the graphite structures in the core.

As the operation of RCCS, the core temperature decreases gradually and the oxidation reaction is terminated. Therefore, the integrity of the graphite structure is maintained through the accident,

\subsection{Forced convection or circulation of water with pumps}

The RCCS at the HTTR adopts forced convection or circulation of water as the working fluid using electrical or mechanical pumps which is a conventional technology. The cooling performance when using forced convection of water was calculated. The calculation conditions are as follows:

Table 2. Forced convection or circulation of water with pumps

\begin{tabular}{|l|l|}
\hline Water temperature in the RCCS & $\begin{array}{l}\text { Approximately } 323.15(\mathrm{~K})= \\
50\left({ }^{\circ} \mathrm{C}\right)\end{array}$ \\
\hline Structure temperature of the RCCS & $\begin{array}{l}\text { Approximately } 373.15(\mathrm{~K})= \\
100\left({ }^{\circ} \mathrm{C}\right)\end{array}$ \\
\hline $\begin{array}{l}\text { Temperature difference between the RPV of } \mathbf{6 7 3 . 1 5}(\mathbf{K}) \\
=\mathbf{4 0 0}\left({ }^{\circ} \mathbf{C}\right) \text { and the structure of the RCCS } \mathbf{3 7 3 . 1 5}(\mathbf{K})= \\
\mathbf{1 0 0}\left({ }^{\circ} \mathbf{C}\right)\end{array}$ & $300(\mathrm{~K})$ \\
\hline
\end{tabular}




\subsection{RCCS using natural convection or circulation of air without chimney effect}

The cooling performance when utilizing the natural convection of air without the chimney effect was calculated. The calculation conditions are as follows:

Table 3. RCCS using natural convection or circulation of air without chimney effect

\begin{tabular}{|l|l|}
\hline Temperature of the structure of the RCCS & $\begin{array}{l}\text { Approximately } 373.15(\mathrm{~K})=100 \\
\left({ }^{\circ} \mathrm{C}\right)\end{array}$ \\
\hline Ambient air temperature in summer season & $313.15(\mathrm{~K})=40\left({ }^{\circ} \mathrm{C}\right)$ \\
\hline Air temperature in the RCCS & $\begin{array}{l}\text { Approximately } 313.15(\mathrm{~K})= \\
\text { approximately } 40\left({ }^{\circ} \mathrm{C}\right)\end{array}$ \\
\hline $\begin{array}{l}\text { Temperature difference between the RPV of } \\
\mathbf{6 7 3 . 1 5}(\mathbf{K})=\mathbf{4 0 0}\left({ }^{\mathbf{0}} \mathbf{C}\right) \text { and the structure of the } \\
\text { RCCS 373.15 }(\mathbf{K})=\mathbf{1 0 0}\left({ }^{\mathbf{0}} \mathbf{C}\right)\end{array}$ & $300(\mathrm{~K})$ \\
\hline Circumference of the surface on the RCCS & $24.2531(\mathrm{~m})$ \\
\hline $\begin{array}{l}\text { Heat transfer coefficient between the RCCS and } \\
\text { air without chimney effect }\end{array}$ & $5\left(\mathrm{~W} / \mathrm{m}^{2} / \mathrm{K}\right)$ \\
\hline
\end{tabular}

The heat transfer area and height necessary to remove $800(\mathrm{~kW})$ are defined as follows:

$\checkmark \quad$ Heat transfer area: $2666.7\left(\mathrm{~m}^{2}\right)$

$$
\frac{800000}{5 \times(373.15-313.15)}=2666.7
$$

$\checkmark \quad$ Height: $109.95(\mathrm{~m})$

$$
\frac{2666.7}{24.2531}=109.95
$$

The temperature of the structure of the RCCS needs to be $373.15(\mathrm{~K})=100\left({ }^{\circ} \mathrm{C}\right)$ to remove $800(\mathrm{~kW})$ by radiation; therefore, the heat transfer area and height need to be $2666.7\left(\mathrm{~m}^{2}\right)$ and $109.95(\mathrm{~m})$, respectively. The required height is apparently too high to be implemented in HTTR.

\subsection{RCCS using natural convection or circulation of air with the chimney effect}

The cooling performance when utilizing the natural convection of air with the chimney effect was calculated. The calculation conditions are as follows:

Table 4. RCCS using natural convection or circulation of air with chimney effect

\begin{tabular}{|l|l|}
\hline Height & $16.8574(\mathrm{~m})$ \\
\hline Heat transfer area & $408.84\left(\mathrm{~m}^{2}\right)$ \\
\hline
\end{tabular}

The heat transfer coefficient between the RCCS and air with the chimney effect necessary to remove $800(\mathrm{~kW})$ are defined as follows:

$\checkmark \quad$ Heat transfer coefficient: $32.6\left(\mathrm{~W} / \mathrm{m}^{2} / \mathrm{K}\right)$

$$
\frac{800000}{408.84 \times(373.15-313.15)}=32.6
$$


The temperature of the structure of the RCCS needs to be $373.15(\mathrm{~K})=100\left({ }^{\circ} \mathrm{C}\right)$ to remove $800(\mathrm{~kW})$ by radiation; therefore, the heat transfer coefficient with the chimney effect needs to be $32.6\left(\mathrm{~W} / \mathrm{m}^{2} / \mathrm{K}\right)$, which is very difficult to achieve for natural circulation air flow.

The RCCS needs long length ducts including ducts from outside the reactor building to the RCCS for utilization of ambient air to enhance chimney effect and increase air velocity for promoting the natural convection or circulation until strong wind; however, the ducts have a maximum limit of the length in the reactor building and the air has a maximum velocity owing to surface resistance on the ducts. Moreover, ambient air always flows into the ducts and dusts including plants and insects are accumulated in the ducts every day. Soon, the ducts are rusted and eroded owing to humidity and salty air; therefore, it is necessary to reserve big-budget and replace the ducts.

\subsection{The proposed new RCCS using novel shape}

A new RCCS using a novel shape is proposed to be implemented in HTTR as shown in Figure 1. The RCCS has air as the heat transport medium. The reactor cavity of the RCCS is enlarged, including two regions, such as an ex-RPV region and a cooling region attached to the top of the RPV region.

From the RPV, it flows upward to the cooling region, the heat transfer area of which is large, and the air is cooled by exchanging heat with the ambient air. The large temperature difference between the coolant and ambient air facilitates heat removal.

The cooling regions feature two or three heat transfer areas, such as the interior, outside and top surfaces. Moreover, the heat transfer areas can easily be increased by machining surfaces or adding fins; therefore, the height of the RCCS can be decreased despite the small heat transfer coefficient on the RCCS outer surface without the chimney effect: $5\left(\mathrm{~W} / \mathrm{m}^{2} / \mathrm{K}\right)$.

The RCCS can passively remove $800(\mathrm{~kW})$ under the following conditions:

$\checkmark$ Heat transfer coefficient between the RCCS and air without the chimney effect: 5 $\left(\mathrm{W} / \mathrm{m}^{2} / \mathrm{K}\right)$

$\checkmark$ Ambient air temperature in summer the season: $313.15(\mathrm{~K})=40\left({ }^{\circ} \mathrm{C}\right)$

$\checkmark \quad$ Pressure in the RCCS: Atmospheric pressure (atm A), 0.101325 (MPa A)

$\checkmark$ Red lines of the RPV region in the RCCS as shown in Fig.1: Adiabatic condition with consideration for safety margin

$\checkmark \quad$ Heat flux on the surface of the RPV: $3.2829\left(\mathrm{~kW} / \mathrm{m}^{2}\right)$

$\checkmark \quad$ Base mesh size: approximately $9(\mathrm{~cm})$

$\checkmark$ Material name: Austenitic Stainless Steel

$\checkmark \quad$ Material properties: $8\left(\right.$ ton $\left./ \mathrm{m}^{3}\right), 502.0\left(\mathrm{~J} / \mathrm{kg} /{ }^{\circ} \mathrm{C}\right), 16\left(\mathrm{~W} / \mathrm{m} /{ }^{\circ} \mathrm{C}\right)$

$\checkmark$ K-Epsilon Turbulence Models

The simulation results from a commercial CFD code, STAR-CCM+ (CD-Adapco, 2012), show that the temperature distribution of the RCCS could be lower than the maximum temperature limits of the structures, such as the maximum operating temperature of the RPV, $713.15(\mathrm{~K})=440\left({ }^{\circ} \mathrm{C}\right)$, and that the heat released from the RPV could be safely removed. Thus, the capacity of the RCCS design is sufficient for decay heat removal.

STAR-CCM+ is a commercial computer-aided engineering package developed by CD-adapco. Originally developed for computational fluid dynamics (CFD) simulations, it has been 
expanded to include additional continuum mechanics models, most notably heat transfer and solid stress models.

The temperature distribution of the RCCS is shown in Figure 1. The average temperatures of the RPV region and the cooling one are about $500(\mathrm{~K})=227\left({ }^{\circ} \mathrm{C}\right)$ and about $400(\mathrm{~K})=127\left({ }^{\circ} \mathrm{C}\right)$, respectively.

However, the maximum temperature in Figure 1 can be decreased because a part of the released heat of $800(\mathrm{~kW})$ can be removed through the boundary conditions of the RPV region.

The cooling regions have two or three heat exchange surfaces, such as inside, outside and top surfaces.

New Reactor Cavity Cooling System can remove $800(\mathrm{~kW})$ passively under the following conditions;

$\checkmark$ Heat transfer coefficient between the RCCS and ambient air without chimney effect: 5 $\left(\mathrm{W} / \mathrm{m}^{2} / \mathrm{K}\right)$

$\checkmark$ Ambient air temperature in summer season: $313.15(\mathrm{~K})=40\left({ }^{\circ} \mathrm{C}\right)$

$\checkmark \quad$ The pressure in the RCCS: Atmospheric pressure (atm A), $0.101325(\mathrm{MPa} A)$

$\checkmark$ Heat flux on the surface of the RPV: 3.2829 $\left(\mathrm{kW} / \mathrm{m}^{2}\right)$

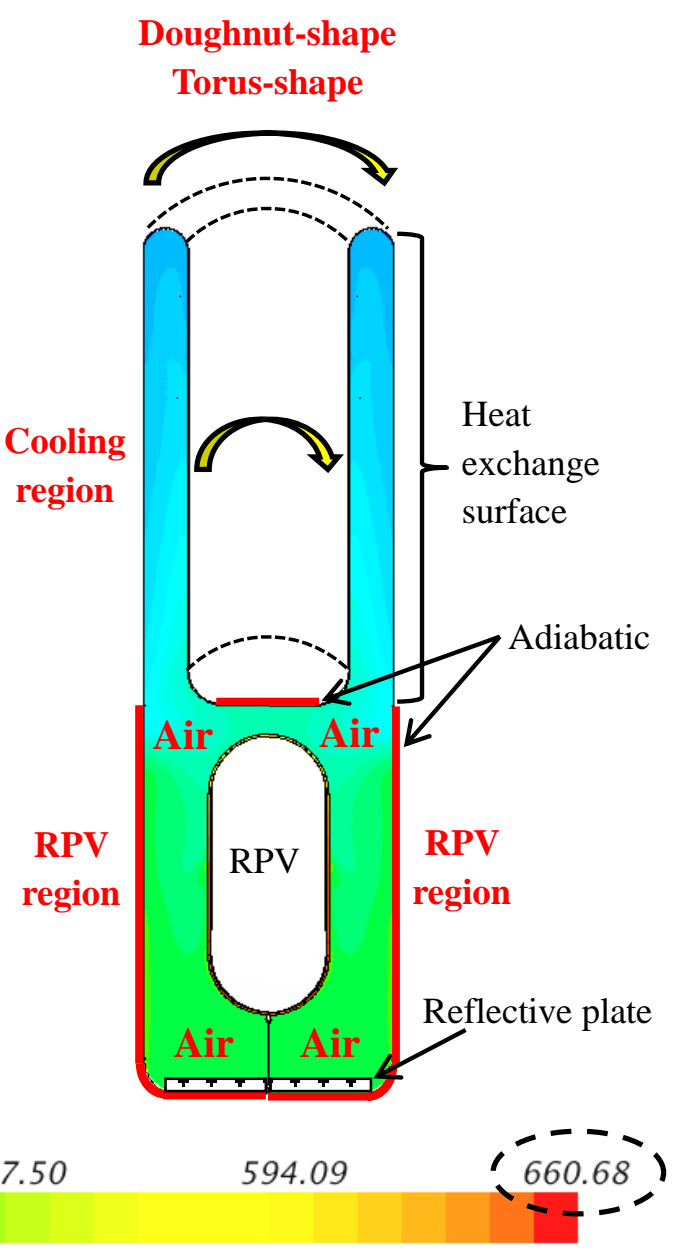

Fig. 1 Temperature distribution of a new RCCS using a novel shape.

When a conventional technology using water as the working fluid in electrical or mechanical pumps is employed, the water reaches the boiling point.

Conversely, when the temperature difference between the cooling region and ambient air is larger, the amount of heat removed from the RCCS to the ambient air increases.

The ratio between the radiation and natural convection of the heat transfer mechanisms from the RPV to ambient air through the RCCS is shown in Figure 2-3. Most of the heat transfer 
mechanisms from the RPV to the RCCS in Figure 2 and from the RCCS to the ambient air in Figure 3 are radiation. Note that the heat transfer coefficient between the RCCS and ambient air is assumed at $5\left(\mathrm{~W} / \mathrm{m}^{2} / \mathrm{K}\right)$ without the chimney effect; therefore, the ratio of the natural convection heat transfer mechanisms from the RCCS to the ambient air will be increased when the heat transfer coefficient with the chimney effect is implemented, which also will increase the amount of heat removed by natural convection.

Conversely, the heat transfer mechanisms in the RCCS are radiation and natural convection at the similar rates; therefore, rounding the corners of the RCCS is very effective to enhance the natural convection in the RCCS. Moreover, we aim to install reflective plates on the bottom to reflect radiation to the upper region.

The pressure limit of the RCCS is $4.0\left(\mathrm{~kg} / \mathrm{cm}^{2} \mathrm{G}\right), 0.39227(\mathrm{MPa} \mathrm{G})$; therefore, when the pressure of air in the RCCS is increased by applying pressure, the pressurized air can remove the heat released from the RPV easily with natural convection.

The $800(\mathrm{~kW})$ discharged from the RPV is equivalent to $2.67(\%)$ of the decay heat of the rated operation of $30(\mathrm{MW})$ at the elapsed time of $40-100(\mathrm{sec})$ after reactor shutdown. It is therefore confirmed that the decay heat and the stored heat (in the fuel and the large amount of graphite in the core) of HTTR after reactor shutdown can be removed by the proposed RCCS for a long time.

In addition, the new RCCS adopts a doughnut- or torus-shape for earthquake proofing. 

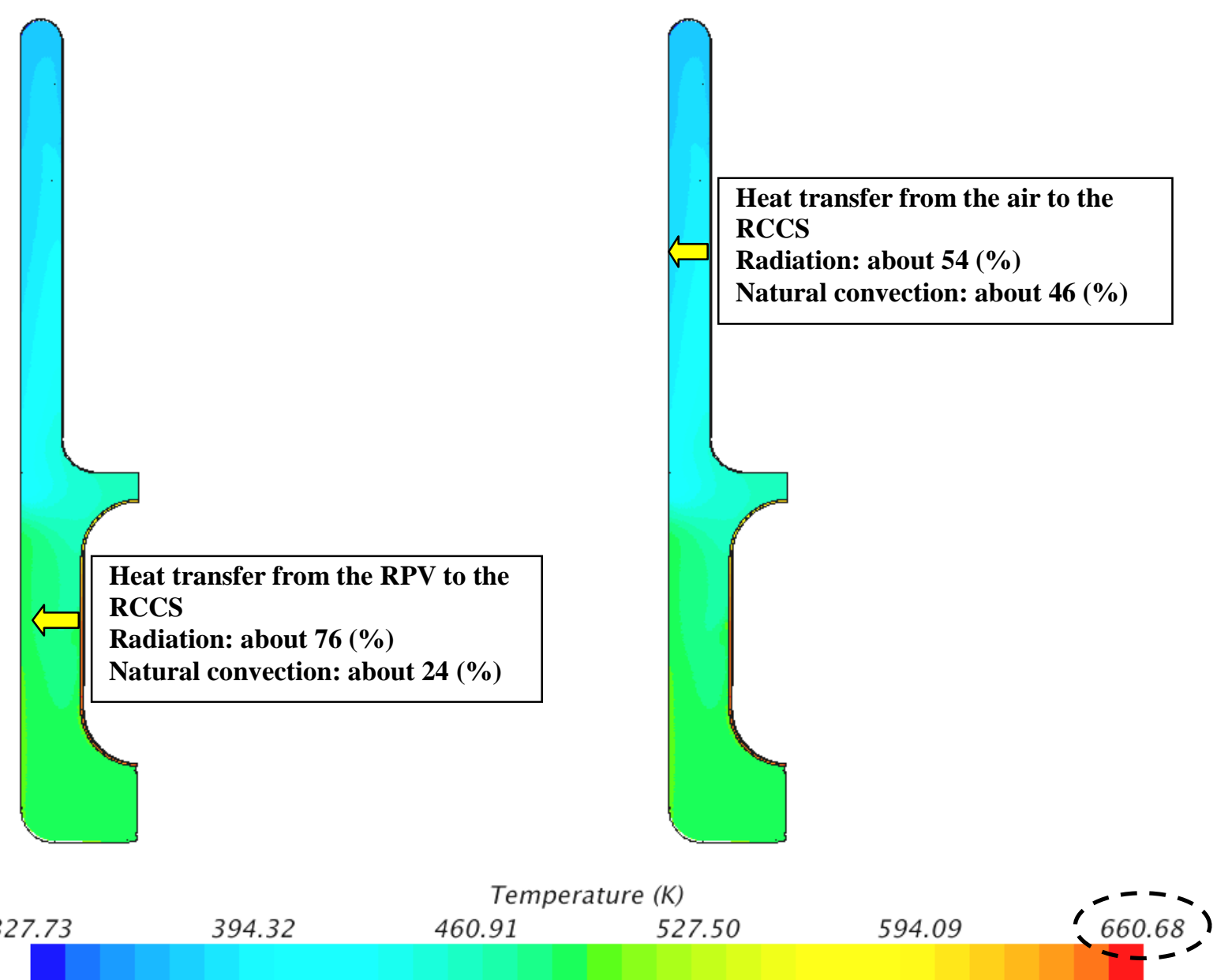

Fig. 2 The ratio between the radiation and natural convection heat transfer mechanisms. 


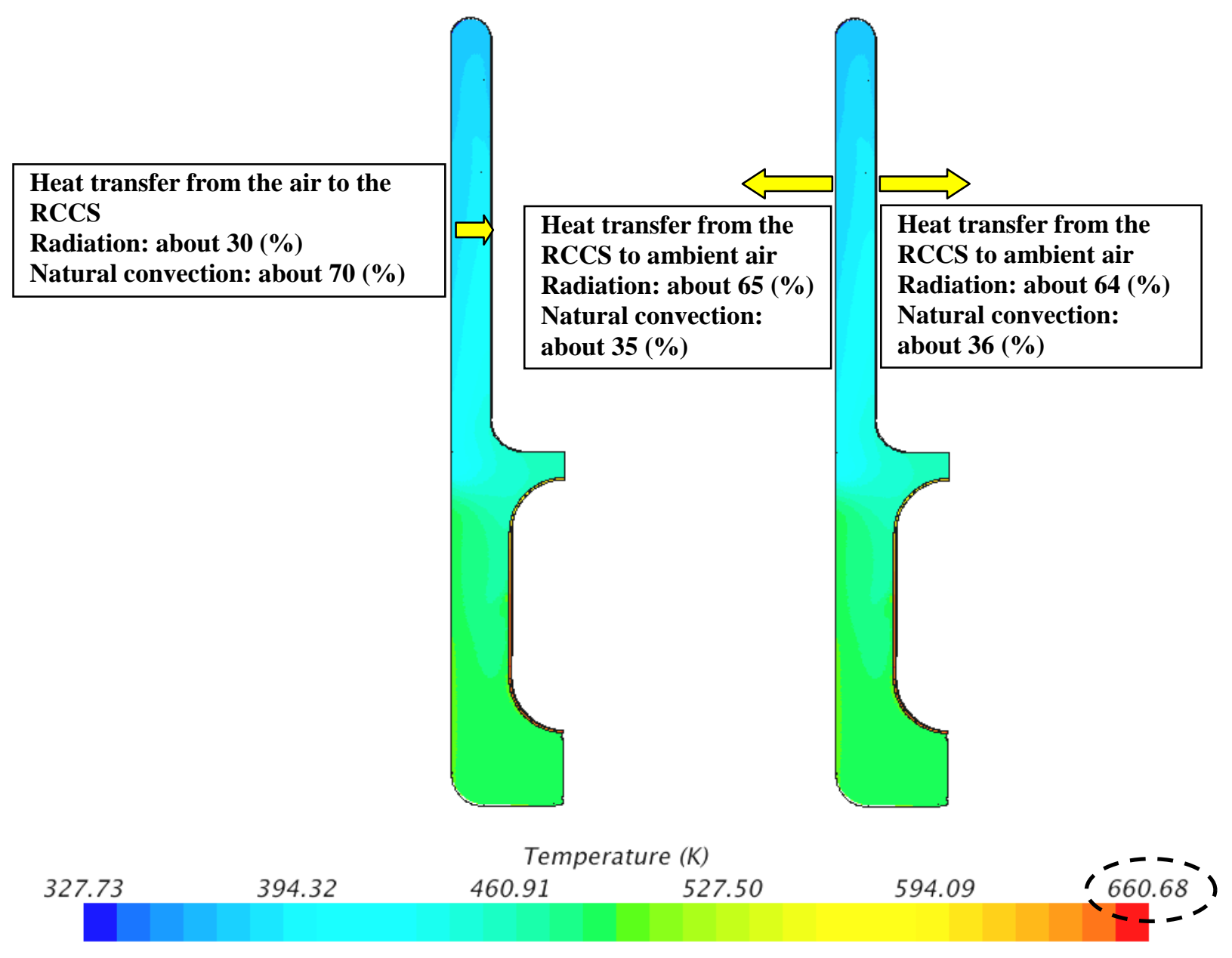

Fig. 3 The ratio between the radiation and natural convection heat transfer mechanisms. 


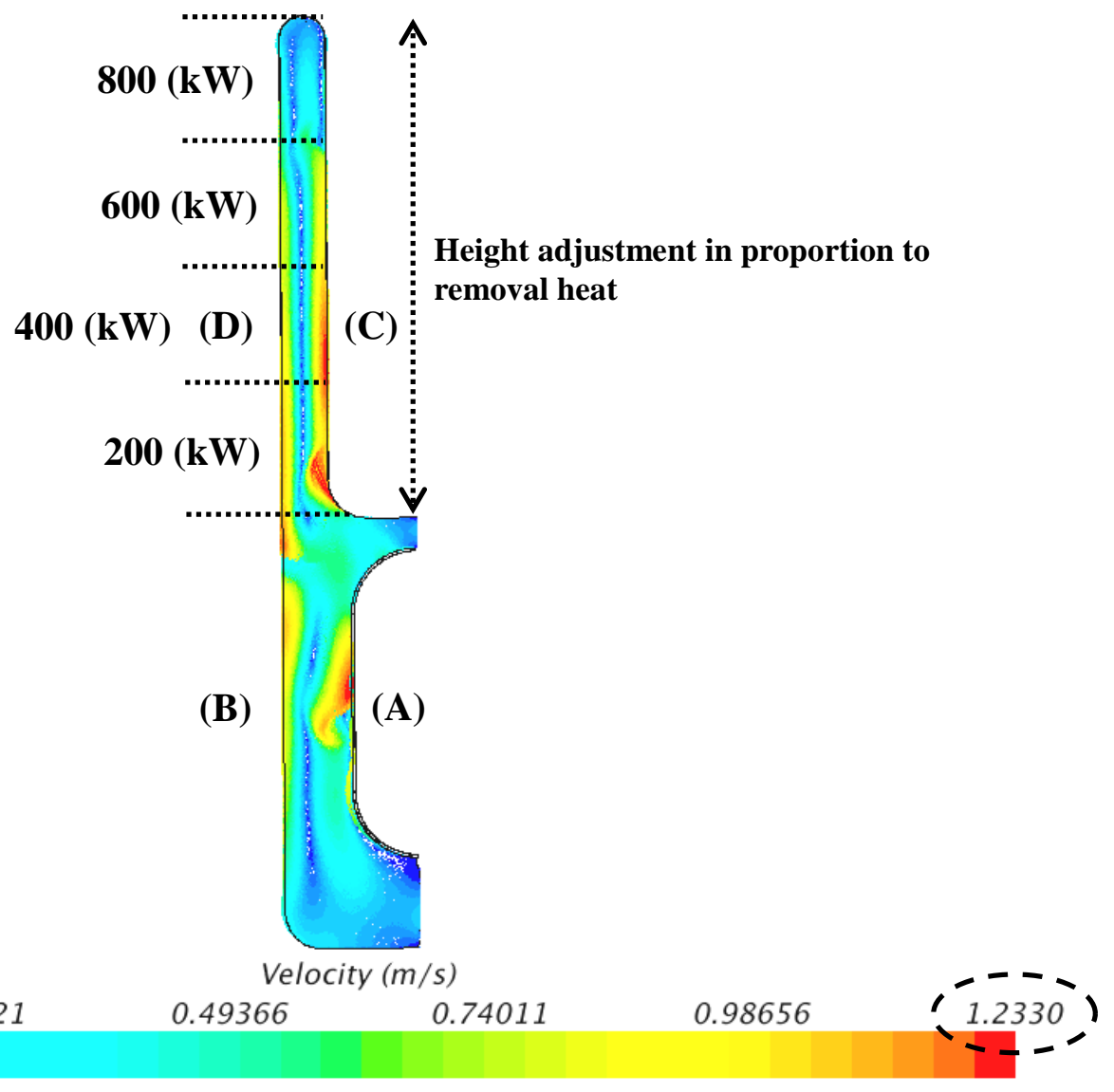

Fig. 4 Velocity distribution of a new RCCS using novel shape.

The velocity distribution of the RCCS is shown in Figure 4.

The velocity is high and natural convection occurs at four positions: the surface (A) on the RPV, the opposite surface (B) to the RPV, and the heat exchange surfaces (C) and (D) with the ambient air.

$\checkmark \quad$ The air at the surface (A) absorbs heat from the RPV by natural convection.

$\checkmark$ The surface (B) opposite to the RPV is heated by radiation from the RPV.

$\checkmark$ The surfaces of the cooling region (C) and (D) are cooled by exchanging heat with the ambient air.

However, the highest velocity is approximately $1.2(\mathrm{~m} / \mathrm{s})$, light air, and the air in the RCCS is relative calm without relying on the chimney effect.

\subsection{Heat pipe}

The utilization of a heat pipe as shown in Figure 5 (Dunn and Reay, 1982) has also been assessed; however, some problems were found. Coolant can be lost in case of a pipe break accident. When the boiling temperature of the coolant is increased by applying pressure, the pressurized coolant is easily lost if a pinhole is present on the surface. For example, saturated water vapor is as follows: 
Table 5. Saturated water vapor

\begin{tabular}{|c|c|}
\hline Temperature $\left({ }^{\mathbf{0}} \mathbf{C}\right)$ & $\begin{array}{c}\text { Saturated pressure } \\
(\mathbf{M P a})\end{array}$ \\
\hline 100 & 0.1014 \\
\hline 150 & 0.4761 \\
\hline 200 & 1.555 \\
\hline 260 & 4.692 \\
\hline 300 & 8.588 \\
\hline
\end{tabular}

The boiling temperature of water of $0.4761(\mathrm{MPa})$ achieves $150\left({ }^{\circ} \mathrm{C}\right)$, and the temperature difference between the pressurized water and ambient air is much smaller than we expects. Small temperature differences do not easily facilitate heat removal from the coolant to the ambient air in case of the heat transfer coefficient between the RCCS and ambient air without chimney effect, $5\left(\mathrm{~W} / \mathrm{m}^{2} / \mathrm{K}\right)$. In other words, the temperature difference between the pressurized water and ambient air positively correlates with the amount of heat that can be removed.

Moreover, when heated above a certain temperature, all of the working fluid in the heat pipe vaporizes, the pressure becomes very high and the heat pipe will be ruptured.

On the other hand, below a certain temperature, the working fluid will not undergo phase change, and the thermal conductivity is reduced to that of the solid metal casing.

Therefore, it is difficult to find working fluids with temperature range from 50 through 450 $\left({ }^{\circ} \mathrm{C}\right)$ during HTTR operations as the RCCS in consideration of irradiation damages.

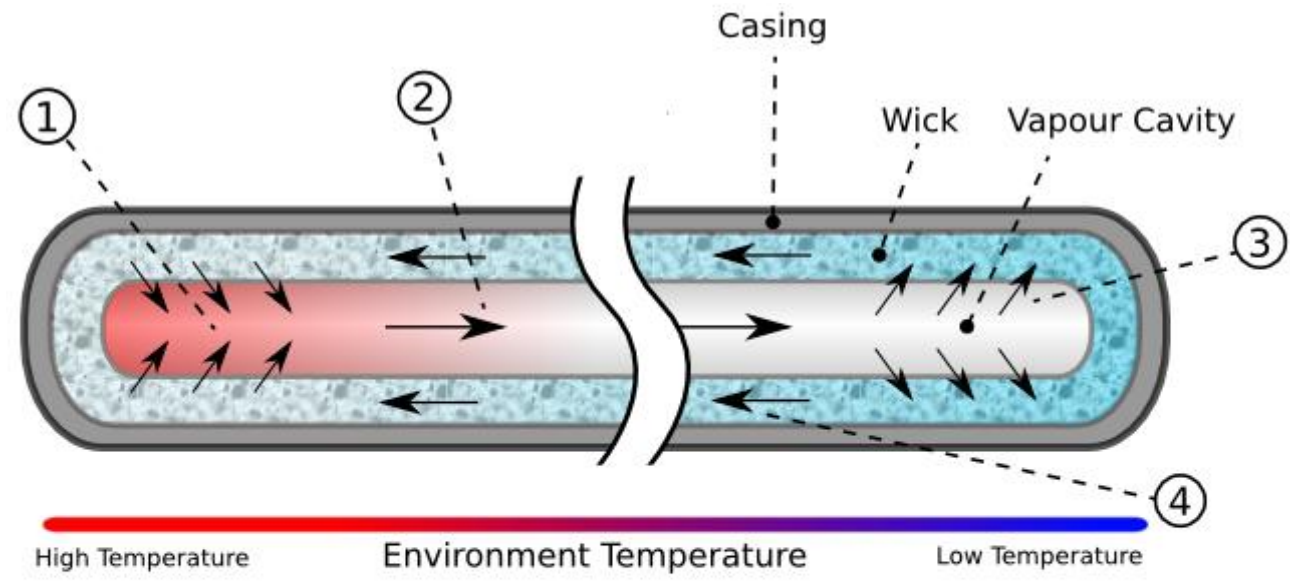

Heat pipe thermal cycle

1) Working fluid evaporates to vapour absorbing thermal energy.

2) Vapour migrates along cavity to lower temperature end.

3) Vapour condenses back to fluid and is absorbed by the wick, releasing thermal energy

4) Working fluid flows back to higher temperature end.

Fig. 5 Heat pipe concept. 


\subsection{Future Plan}

Some of the future analyses and experiments include the following:

A downsized new RCCS can be designed and built for demonstration experiments at the Natural convection Shutdown heat removal Test Facility (NSTF) at the Argonne National Laboratory (ANL), as shown in Figure 6 (Argonne National Laboratory, 2014).

$\checkmark$ Surveys to assess parameters that influence the amount of heat removed, such as the heat flux on the RPV, ambient air temperature, emissivity, etc., can be demonstrated.

The NSTF is a state-of-the-art, large-scale facility for evaluating the performance capabilities of decay heat removal systems. NSTF's purpose is to

1. Examine the passive safety of future nuclear reactors;

2. Provide a user facility to explore alternative reactor design concepts; and

3. Generate benchmarking data to validate advanced computer simulations.

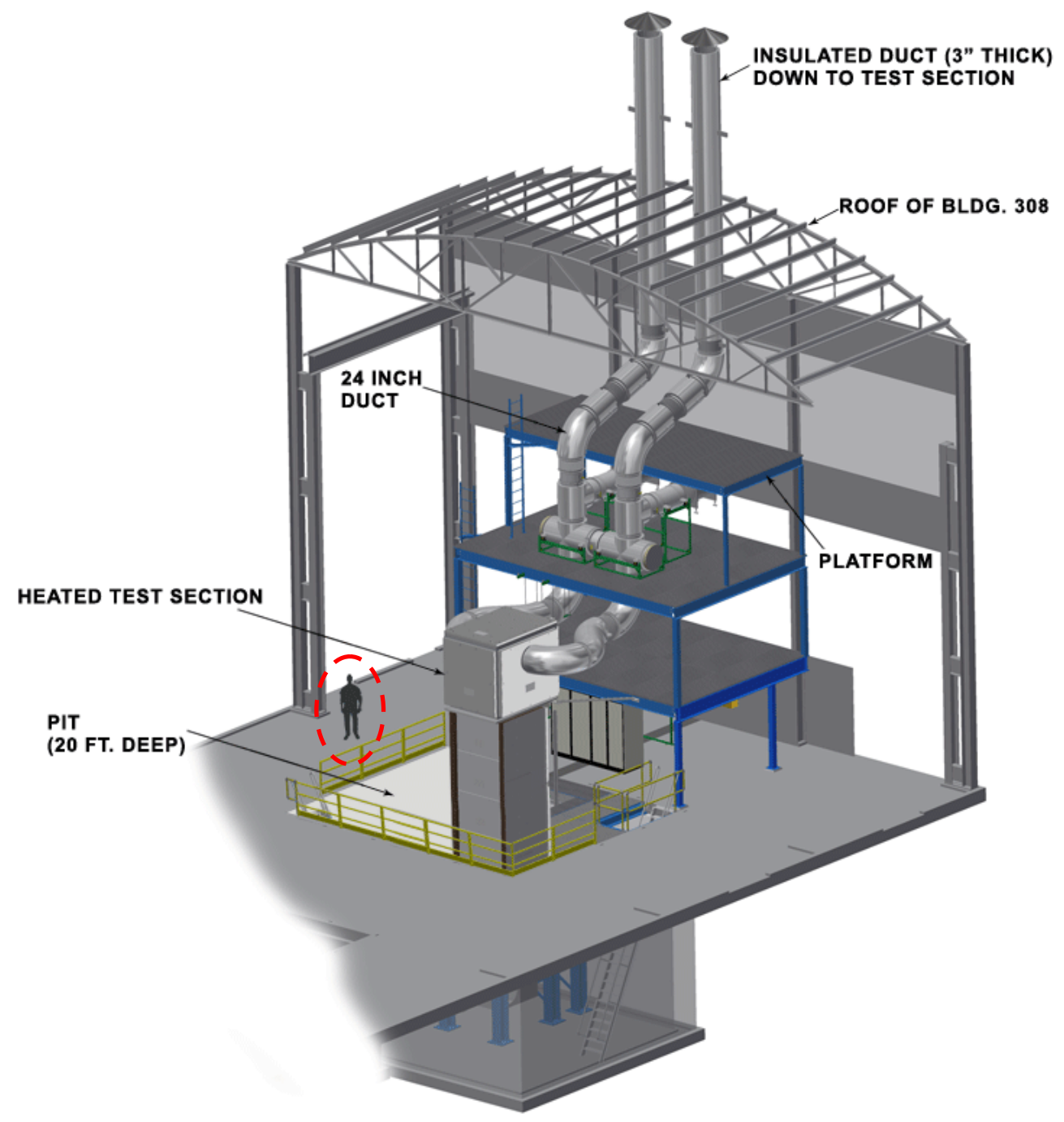

Fig.6 Natural convection Shutdown heat removal Test Facility (NSTF) at the ANL.

$\checkmark$ The adoption of the new RCCS for other nuclear reactors, such as LRW or SFR, is 
considered.

$\checkmark \quad$ The earthquake resistance of the new doughnut- or torus-shaped RCCS is assessed.

\section{CONCLUSIONS}

The heat released from the core or the RPV due to the Fukushima Daiichi accident could not be actively or passively removed, which ultimately resulted in partial core melting; therefore, we propose a new RCCS that utilizes a novel shape to avoid the loss of the heat sink and core meltdown during any nuclear accident, including a station blackout. The RCCS can always stably and passively remove a part of the released heat at the rated operation and the decay heat after reactor shutdown.

Specifically, emergency power generators are not necessary and the decay heat can be passively removed for a long time, even forever if the heat removal capacity of the RCCS is sufficient.

This R\&D effort on the RCCS concept would help improve the safety and public acceptance of nuclear energy worldwide.

\section{ACKNOWLEDGMENTS}

Argonne National Laboratory's work is supported by the U.S. Department of Energy, Office of Nuclear Energy under Contract \# DE-AC02-06CH11357. The authors would like to express their gratitude to Dr. Thomas Y. C. Wei at Argonne National Laboratory for his valuable comments and advise throughout this work.

\section{REFERENCES}

Argonne National Laboratory, 2014. Passive Safety and Decay Heat Removal for Advanced Nuclear Reactor Designs (NSTF). <http://www.ne.anl.gov/capabilities/rsta/nstf/index.shtml >.

CD-Adapco, 2012. User Guide, STAR-CCM+ Version 7.02. New York, USA.

Dunn, P.D., Reay, D.A., 1982. Heat Pipes, third ed. Pergamon Press Ltd., England.

Katanishi, S., Kunitomi, K., Tsuji, N., Maekawa, I., 2004. Design Study on Passive Cooling System of the Gas Turbine High Temperature Reactor (GTHTR300), J. At. Energy Soc. Jpn., 3, 3, 257-267.

Lomperski, S., Pointer, W. D., Tzanos, C. P., Wei, T. Y. C., Kraus, A. R., 2011. Generation IV Nuclear Energy System Initiative. Air-Cooled Option RCCS Studies and NSTF Preparation, ANL-GenIV, 179.

Saito, S. et al., 1994. Design of High Temperature Engineering Test Reactor (HTTR), JAERI, 1332.

Williams, P.M., Silady, F.A., Dunn, T.D., Noren, R.C., McEachern, D.W., Dilling, D.A., Berkoe, J.M., Homan, F.J., Mears, L.D., Penfield, Jr.S.R., Lidsky, L.M., Yan, X.L., Reid, C.L., 1994. MHTGR Development in the United States. Prog. Nucl. Energ., 28, 3, 265-346. 